Article

\title{
Comparative Analysis of Energy Use and Human Comfort by an Intelligent Control Model at the Change of Season
}

\author{
Sung Hoon Yoon ${ }^{1}$ and Jonghoon Ahn ${ }^{2, *}$ \\ 1 Department of Architecture, Cheongju University, Cheongju 28503, Korea; shyoon@cju.ac.kr \\ 2 School of Architecture and Design Convergence, Hankyong National University, Anseong 17579, Korea \\ * Correspondence: architectism@hknu.ac.kr; Tel.: +82-10-5719-5944
}

Received: 6 October 2020; Accepted: 16 November 2020; Published: 18 November 2020

check for updates

\begin{abstract}
For improving control methods in the thermal environment, various algorithms have been studied to satisfy the specific conditions required by the characteristics of building spaces and to reduce the energy consumed in operation. In this research, a network-based learning control equipped with an adaptive controller is proposed to investigate the control performance for supply air conditions with maintaining the levels of indoor thermal comfort. In order to examine its performance, the proposed model is compared to two different models in terms of the patterns of heating and cooling energy use and the characteristics of operational signals and overshoots. As a result, the energy efficiency of the proposed control has been slightly decreased due to the energy consumption increased by precise controls, but the thermal comfort has improved by about $10.7 \%$ more than a conventional thermostat and by about $19.8 \%$ more than a deterministic control, respectively. This result can contribute to the reduction of actual installation and maintenance costs by reducing the operating time of dampers and the energy use of heating coils without compromising indoor thermal comfort.
\end{abstract}

Keywords: energy transfer; thermal comfort; artificial neural network; adaptive controller; changing season

\section{Introduction}

In the field of building thermal controls, several analyses based on mathematical and statistical approaches have been conducted to investigate the thermal control strategies for cooling and heating as spatial characteristics. Among the several control rules, the integral and derivative methods of the signals have been commonly used with manual and computing tools to improve the performance of generators, exchangers, distributers, and economizers in the Heating, Ventilation, and Air Conditioning (HVAC) systems. In order to retrofit old systems using limited resources and data, the current control algorithms have examined a higher level of optimized signals by utilizing several parameters in variables. By use of advanced tuning rules, the precise controls of fuel, damper, valve, fan motor speed, and resistance coil were examined, and the variations of heating and cooling load patterns were investigated in building components [1-3].

As computing software and hardware were developed, the inner structures of thermal control models were rapidly improved to reduce physical and chemical resources. In the simulation fields, the utilization of the Fuzzy Inference System (FIS) and the Artificial Neural Network (ANN) was able to assist many researchers to theoretically and practically approach high complex and difficult problems that they have never tried to calculate before. The FIS algorithm utilizes linguistic approaches to complement fixed number or linear models in parametric controls that revealed some limitations of the conventional reasoning. By using the differences and the derivatives of serial control signals in 
thermal models, the system was able to investigate to define better controlled signals to improve the efficiency for fuel use in boiler systems and the operational distribution advantages in thermal networks. As compared to conventional control algorithms, the FIS has provided highly improved control signals for ambiguous situations where simple mathematics cannot determine appropriate signals [4-6]. By using specific genetic algorithms derived from data-driven regression models and lab-scaled experiments, the signal modification by the FIS model has concluded quite effective results at many cases of the HVAC systems [7,8]. In addition, the ANN algorithm has utilized to approach several problems which have quite complex inner structures and correlations in the cases that the number of calculations exponentially increases after only a few variables added. The ANN-based control methods from the comprehensive comparisons were used to define more realistic energy use or assess energy performance by use of several iterations of networks. Especially, it has provided very efficient solutions in the areas of analyzing day-lighting impacts, indoor air ventilation and infiltration, and surface heat radiance, which has a high likelihood of having hidden correlations [9-11]. The diversified ANN structures have been able to deal with multivariate regression models affected by sensitive changes in numbers in distribution network models dealing with controlling dampers or valves in duct works. This means combining theoretical and experimental systems in association with real-time changes in thermal demands defined by the conditions of mechanical and architectural components. In specific models, combined approaches of dampers and resistance coils were tested by use of regression models to effectively respond to thermal demands in association with building geometries and outdoor temperature. Its control performance was confirmed as a high statistical validity by 0.7797 of the root mean square error and by 0.9998 of $R^{2}$ [12]. In the research for combining the FIS and ANN algorithms in a single network, the performance was confirmed quite effective in terms of mitigating an increase in energy use, by 26.1 to $44.1 \%$, despite highly precise controls to increase thermal comfort by 2.5 to $4.3 \%[13,14]$.

For improving thermal comfort levels in buildings, there have been several indices reflecting building geometries, weather conditions, and occupant behaviors. Amongst these, due to advantages of explaining the thermal comfort most directly to the users, several survey-based studies were examined to improve the analytic performance of subjective indices based on advanced statistical tools [15-17]. Unlike the subjective analyses, the Predicted Mean Vote (PMV) and the Predicted Percentage of Dissatisfied (PPD) also have been used through the objective numbers, parameters, and mathematics such as mean radiant temperature, air speed, relative humidity, and thermal clothing insulation. By adopting the deterministic model by using the FIS and the ANN, many systems were able to be effectively analyze to assess and predict more precise thermal sensation votes in conventional rule based PMV indices. According to genetic algorithms and data-driven models for improving conventional control rules, occupant responses were used to improve control strategies and their energy efficiency associated with various design assumptions about users' characteristics [18,19]. The conditions of building envelopes for thermal demands were diversified to define some hidden correlations of architectural element, and meanwhile, several traditional indices were also utilized to define the performance of remodeled or retrofitted thermal environments reflecting recent guidelines and regulations [20,21]. The FIS approaches were frequently used to define the effects of human factors in mathematical sensation votes. Several design situations assuming specific occupant characteristics, such as types of works and clothes, were considered to examine reliable and accurate calculations for the PMV and PPD results. Like the approaches for the HVAC systems, genetic algorithms derived from experimental data were utilized to define several functions for ambiguous situations to control the appropriate levels of indoor thermal comfort by 20.0 to $33.6 \%$ of the PPD index [22]. Additionally, some useful cosimulation computing programs can have researchers investigate interactive methods between the thermal calculation and the computing language programs, which were mainly utilized to immediately modify and correct signals by use of connecting common variables in those programs $[23,24]$. Energy conservation measures, such as exterior envelopes, indoor partitions, fenestrations, bulbs, heaters, and coolers, were adopted to complement some weaknesses of specific 
results mainly based on mechanical systems. Recent approaches by deterministic and data-driven algorithms focused on improving validity of interactions between the energy conservation measures, so some proposed models adopted multilayered matrixes utilizing huge data from repeated simulations and disciplinary experimental models $[25,26]$.

In a number of research works, several approaches have been conducted to reduce energy consumption of buildings, and corresponding works have been also carried out to improve users' thermal comfort. However, when finding strategies to improve both of the performances at the same time, the precise control for better environments could increase energy consumption, and the energy savings would not guarantee maintaining consistent comfort levels. In addition, there might be some disadvantages to optimize supply air conditions for heating or cooling for a room scale at the change of season. In this research, a combined model equipped with an adaptive controller is proposed to investigate the performance of network-based learning algorithm. In Results and Discussion, the control effectiveness of the proposed model is examined by using the comparison with a thermostat and a fuzzy-based controller through the levels of energy transfer and thermal comfort values. In Conclusion, the statistical validity of the proposed network-based approach is confirmed to effectively control heating and cooling supply air for both aspects of energy and comfort.

\section{Methodology}

\subsection{Design Strategy}

In this simulation research, a major purpose is to examine the condition of supply air by use of both controls of the air mass and temperature. A proposed network-based learning model responds to the change of thermal demands while the amount of heat transfer is determined in a day at the change of season. In order to find optimized points, an adaptive controller is connected into the proposed model and complements the thermal signals to increase thermal comfort levels by means of changing set-point temperature. A design strategy for these phases is summarized as follows:

(1) Based on building geometries, outdoor temperature, and occupant characteristics, a thermal energy supply model calculates the heating or cooling supply air conditions for a room by the air amounts and its temperature.

(2) When the supply air conditions are defined, a thermal comfort model calculates the PMV (and PPD) levels of the room.

(3) If the PMV level is out of the range of setting levels $(-0.5<x<0.5)$, an adaptive controller adjusts the set-point temperature by add +0.5 or -0.5 following heating or cooling conditions.

(4) If the PMV level is still out of the range of the setting levels, an adaptive controller repeats the previous phase.

(5) All phases repeat at each one-minute interval, and the models calculate the amount of heat transfer and thermal comfort to result templates.

Figure 1 displays a schematic building model for this simulation research. This model utilizes an Energy + template of the ASHRAE Standard 90.1.2016 OfficeSmall, which includes the information on location, orientation, construction set, material, thermal zone, and internal load. Each wall consists of two layers of $120 \mathrm{~mm}$ concrete and $30 \mathrm{~mm}$ insulation, and each window consists of two layers (double pane) of $6 \mathrm{~mm}$ clear glass. Assuming that the flow rate of air is linearly proportional as in known through several physical experiments, the opening ratio of the damper is directly utilized as the amount of supply air [27]. The conduction of envelopes and fenestrations is one of the major factors for the calculation of the heat loss, but the latent heat from people, lighting, equipment, and machine is not included for the heat gain. In order to save resources for this simulation, air pressure variations by the air flow are neglected. In addition, the air speed in convection and leakage in duct systems are not considered. 


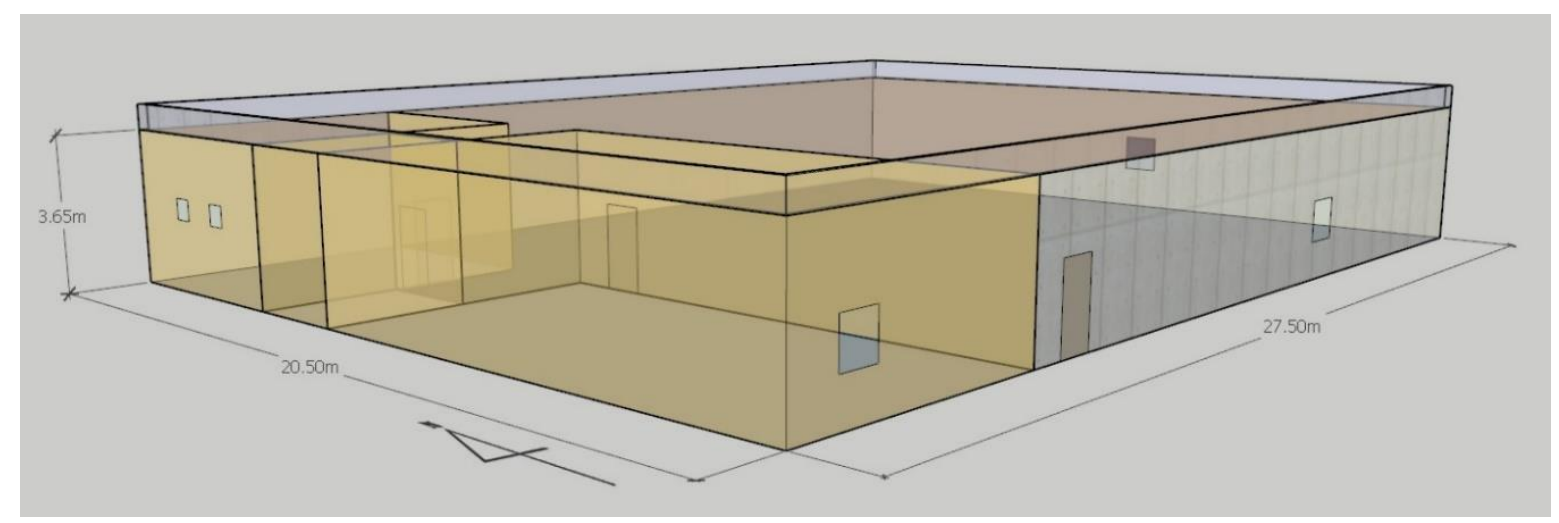

Figure 1. Schematic building model.

Table 1 describes initial design parameters. Except for external work (0), relative humidity (50\%), and air speed $(0.1 \mathrm{~m} / \mathrm{s})$, the thermal comfort factors for the simulation conditions are considered by the references of the ASHRAE standards and the Engineering Toolbox guidelines. A reference model as a comparator utilizes a concept of a conventional thermostat. Another comparator is the FIS as a deterministic control; its algorithm consists of four different membership functions for input variables reflecting its linguistics algorithm. For the ANN as a network-based learning control after completion of under 1000 iterations, as previously mentioned, one adaptive controller works together to define optimize points to mitigate the level of thermal comfort from the PMV or PPD indices.

Table 1. Design parameters.

\begin{tabular}{ccc}
\hline Parameter & Unit & Value \\
\hline Building type & - & OfficeSmall (ASHRAE Standard 90.1.2016) \\
\hline Building Geometry & $\mathrm{m}$ & $27.5(\mathrm{~W})^{*} 20.5(\mathrm{D})^{*} 3.65(\mathrm{H})$ \\
\hline Wall Depth & $\mathrm{m}$ & 0.15 \\
\hline Thermal Conductivity of Wall $\left(k_{\text {wall }}\right)$ & $\mathrm{W} / \mathrm{m} \cdot \mathrm{K}$ & 136.8 \\
\hline Window Area & $\mathrm{m}^{2}$ & 6.0 \\
\hline Window Depth & $\mathrm{m}$ & 0.02 \\
\hline Thermal Conductivity of Window & & 2808.0 \\
\hline$T_{\text {set }}$ for Cooling & $\mathrm{W} / \mathrm{m} \cdot \mathrm{K}$ & 25.5 \\
\hline$T_{\text {set }}$ for Heating & ${ }^{\circ} \mathrm{C}$ & 20.0 \\
\hline Default mass flow-rate into room air & ${ }^{\circ} \mathrm{C}$ & 1470 \\
\hline Users' metabolic rate & $\mathrm{kg}$ & $1.0(1.2$ for 09:00 to 18:00) \\
\hline Users' clothing insulation & $\mathrm{W} / \mathrm{m}^{2}$ & 1.2 \\
\hline Weather condition & $\mathrm{m}^{2} \cdot \mathrm{K} / \mathrm{W}$ & 28 April, Shanghai in China \\
\hline
\end{tabular}

\subsection{Heat Transfer}

From the thermodynamics, the energy loss and gain are given [28]:

$$
Q_{\text {loss }}+Q_{\text {gain }}=\frac{d u}{d t}
$$

where $Q_{\text {loss }}$ is the amount of heat transfer between outside and inside and $Q_{\text {gain }}$ is the amount of heat transfer from a heater, $t$ is the time, and $U$ is the internal energy. 
From the equations for the thermal conductivity, $Q_{\text {loss }}$ is obtained:

$$
Q_{\text {loss }}=\left(T_{r m}-T_{\text {out }}\right) /\left\{\frac{1}{\left(h_{\text {out }} \times A\right)}+\frac{D}{(k \times A)}+\frac{1}{\left(h_{\text {in }} \times A\right)}\right\}
$$

where $h_{\text {out }}$ and $h_{\text {in }}$ are the heat transfer coefficients, $k$ is the transmission coefficient, $A$ is the area, $D$ is the thickness of architectural components.

Regarding the mass flow rate, the enthalpy, and the external and internal work at this system, $Q_{\text {gain }}$ is obtained [28]:

$$
Q_{\text {gain }}=\dot{m}_{h t} C_{p}\left(T_{h t}-T_{r m}\right)
$$

The rate of the internal energy is given:

$$
\frac{d u}{d t}=m_{r m \cdot a i r} C_{v} \frac{d T_{r m}}{d t}
$$

Thus, the derivative of $T_{r m}$ is obtained:

$$
\frac{d T_{r m}}{d t}=\frac{1}{m_{r m \cdot a i r} C_{v}} *\left(\left(\frac{T_{r m}-T_{\text {out }}}{1 /\left(h_{\text {out }} \times A\right)+D /(k \times A)+1 /\left(h_{\text {in }} \times A\right)}\right)+\left(\dot{m}_{h t} C_{p}\left(T_{h t}-T_{r m}\right)\right)\right)
$$

\subsection{Thermal Comfort}

For the mathematical index reflecting thermal comfort, this simulation model utilizes the Predicted Mean Vote (PMV) index. Although various adaptive models have been being developed for user-oriented sensation votes, the PMV is used to clearly compare the advantages and disadvantages of each model $[29,30]$.

$$
\mathrm{PMV}=3.155\left(0.303 e^{-0.114 M}+0.028\right) L
$$

where, $M$ is the metabolic rate, and $L$ is the thermal load.

\subsection{Thermostat Controller}

In this simulation research, a thermostat controller is used to identify the performances of fuzzy-based and network-based models. Its range of the dead-band of turning on and off for the set-point temperature is within $\pm 1^{\circ} \mathrm{C}$ of $T_{\text {set }}$, which is the default setting values in most commercial thermostats. As a working example, if the $T_{r m}$ is larger than $T_{\text {set }}$ by $1{ }^{\circ} \mathrm{C}$, the thermostat control begins to send an on-signal to the cooler or to send an off-signal to the heater.

\subsection{Fuzzy Controller}

The FIS as a deterministic control is used to compare the performance of the proposed model. Like the thermostat, it controls the values of air amounts and its temperature, and its algorithm reflects on $T_{\text {set }}$ and $T_{r m}$. The simple rule of membership functions for two input variables in the FIS inner structure is described as below. The temperature differences between $T_{\text {set }}$ and $T_{r m}$ is described as $E$, and derivative of the temperature difference is as $\Delta E$, which are utilized as two input variables of the fuzzy membership functions [31]. For two output variables, the membership functions for the FIS utilize triangular functions with four different sections as below. For the output, two different FIS controls send each signal for the rate of opening from $0(0 \%)$ to $1(100 \%)$ and for its temperature from -10 to 10 . As the maximum value equals to 1 and the minimum value equals to 0 , the triangular membership functions are defined by [31].

$$
\begin{gathered}
E=T_{\text {set }}-T_{r m} \\
\Delta E=\frac{\left(E_{n}-E_{n-1}\right)}{\Delta t}
\end{gathered}
$$




$$
\begin{array}{r}
\text { if } x \text { is } A \text { and } y \text { is } C \text { then } f_{1}=p_{1} x+q_{1} y+r_{1} \\
x \leq a_{i} \rightarrow 0 \\
\mu(x)=\operatorname{triangle}\left(x ; a_{i}, b_{i}, c_{i}\right)=\left\{\begin{aligned}
x \leq b_{i} & \rightarrow \frac{\left(x-a_{i}\right)}{\left(b_{i}-a_{i}\right)} \\
a_{i} \leq x \leq c_{i} & \rightarrow \frac{\left(c_{i}-x\right)}{\left(c_{i}-b_{i}\right)} \\
b_{i} \leq x \leq 0 & \rightarrow 0
\end{aligned}\right.
\end{array}
$$

\subsection{Network Controller}

As major factors of the ANN structure as a network-based learning algorithm, it is required that several structures need to be defined and that a nonlinear mapping function $x$ with a network needs to be selected. As of the function approximation, the ANN structure consists of two variables for the input layer, 10 weight process for the hidden layer, and one variable as the output layer as indicated in Figure 2 [32,33].

\section{Hidden Layer}

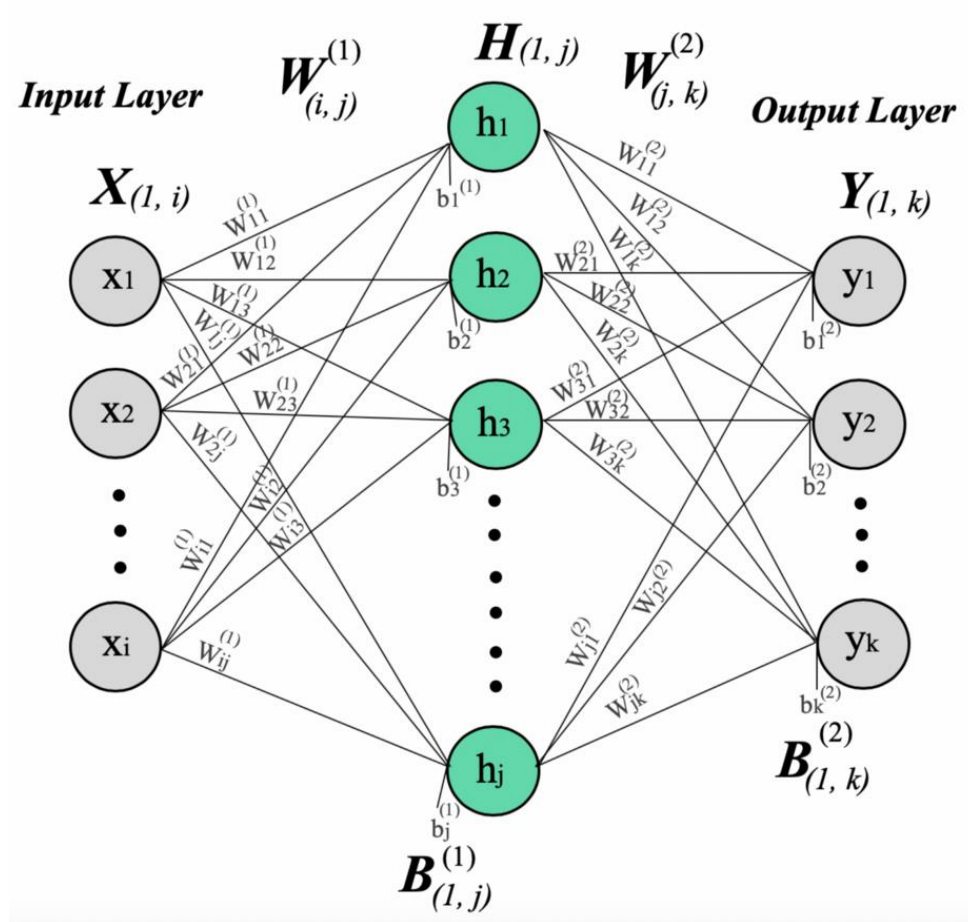

Figure 2. Concept of the artificial neural network.

The inputs $x_{1}, \ldots x_{k}$ to neurons are multiplied by weights $w_{k i}$. Then, they are summed up with the constant bias term $\theta_{i}$. As a consequence, the calculating $n_{i}$ is the input to the activation function $g[32,33]$.

$$
n=\sum_{i=1}^{K} x_{i} \omega_{i}-\theta
$$

The ANN model utilizes two input variables of $E$ and $\Delta E$, and one output for the supply air mass or its temperature from each node of the ANN. It is trained to define optimized patterns that can maintain $T_{r m}$ consistently within the setting ranges of the PMV. As a training algorithm, a scale conjugate gradient algorithm is used, and the repetition of simulations is under 1000 times to 1000 or less, and it is trained to find a better regression model in association with energy use responding to $T_{\text {out }}$. After the validation process, the $R^{2}$ values are confirmed as 0.99652 for controlling the amount of mass and 0.99790 for controlling its temperature, respectively. 


\subsection{Simulation Model}

Figure 3 describes a simulation block diagram. Overall, the simulation model consists of six different modules: Thermostat (Therm in Figure 1); Thermal Energy Supply Model; Control (FIS and ANN in Figure 1); Room; Comfort; Adaptive. In order to effectively control $T_{r m}$ as $T_{\text {set }}$, the thermal energy supply module calculates the amounts of air mass and its temperature to send signals to the room. Based on the results in the room module, the comfort module calculates the PMV levels. From the PMV levels, the adaptive module determines whether $T_{\text {set }}$ needs to be adjusted or not. Regarding this determination, the FIS and ANN modules calculate and send optimized signals to the thermal energy supply module. Then, each phase is repeated in this order at every one-minute time interval for $24 \mathrm{~h}$. Regarding the simulation performance and Equation (5), this model utilizes the concept of a derived function rather than the differentials to measure temperature changes over time. For the development of this model, the ASHRAE standard templates in Energy+ and Open Studio were used. Furthermore, for the simulation per minute, the MATLAB was used to build six modules and to exchange weather data obtained from the IWEC into outdoor temperature signals.

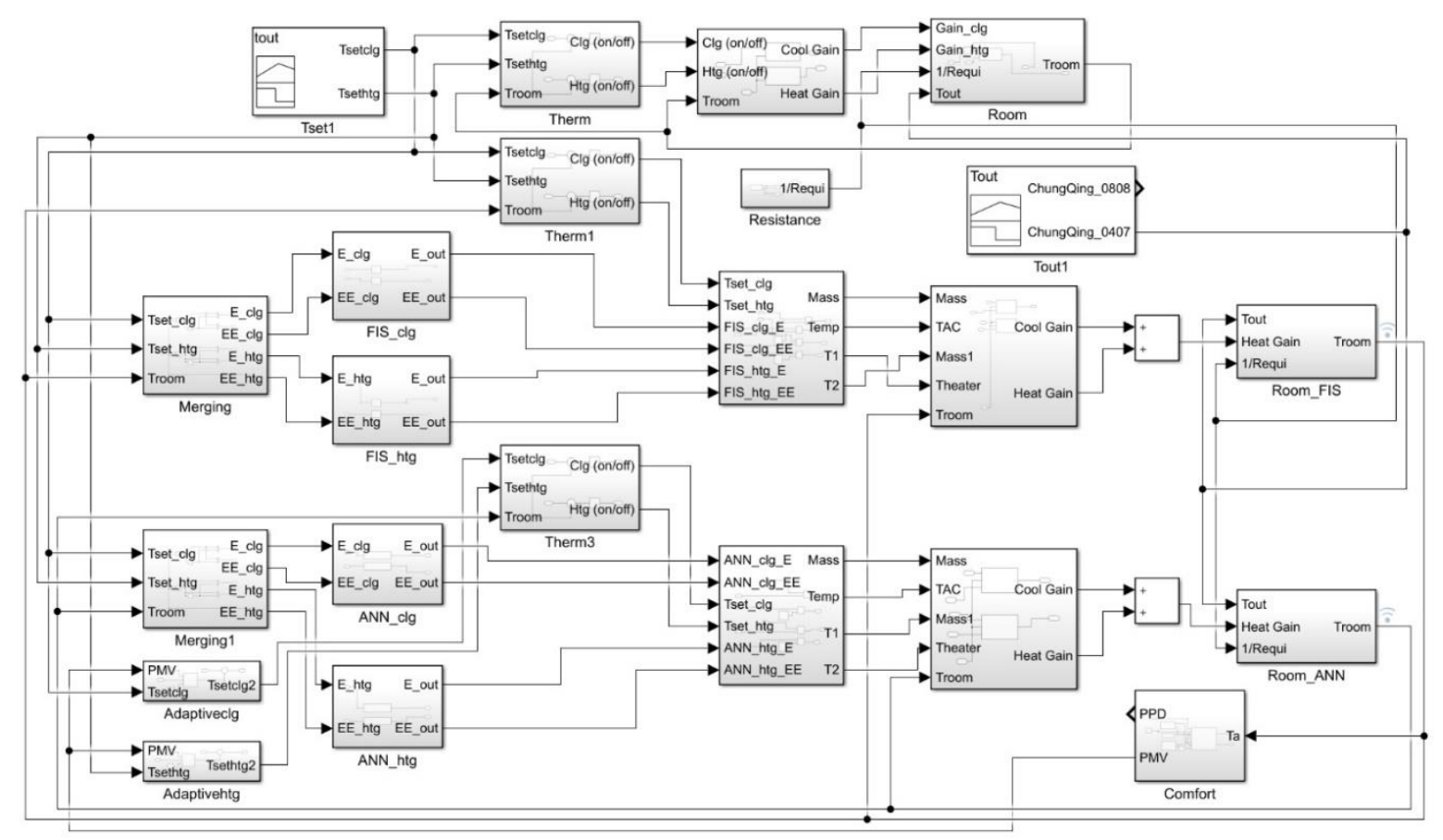

Figure 3. Block diagram.

\section{Results}

\subsection{Room Temperature}

Figure 4 displays the changes in $T_{\text {out }}$ of 28 April, Shanghai in China, and this climate information was retrieved from the International Weather for Energy Calculations. As indicated, uniquely, the daily temperature drops to $16.0^{\circ} \mathrm{C}$ and then rises to $29.0^{\circ} \mathrm{C}$, resulting in a daily temperature difference of $13.0^{\circ} \mathrm{C}$. Figure 5 describes the comparison of $T_{r m}$ by the thermostat, the FIS, and the ANN controls. The range of temperature changes by the thermostat is wide within about $2{ }^{\circ} \mathrm{C}$ but quite regular, so the thermostat control rule may be effective in reducing its energy use, but there is a chance of disadvantages of consistent maintenance for users' thermal comfort. 


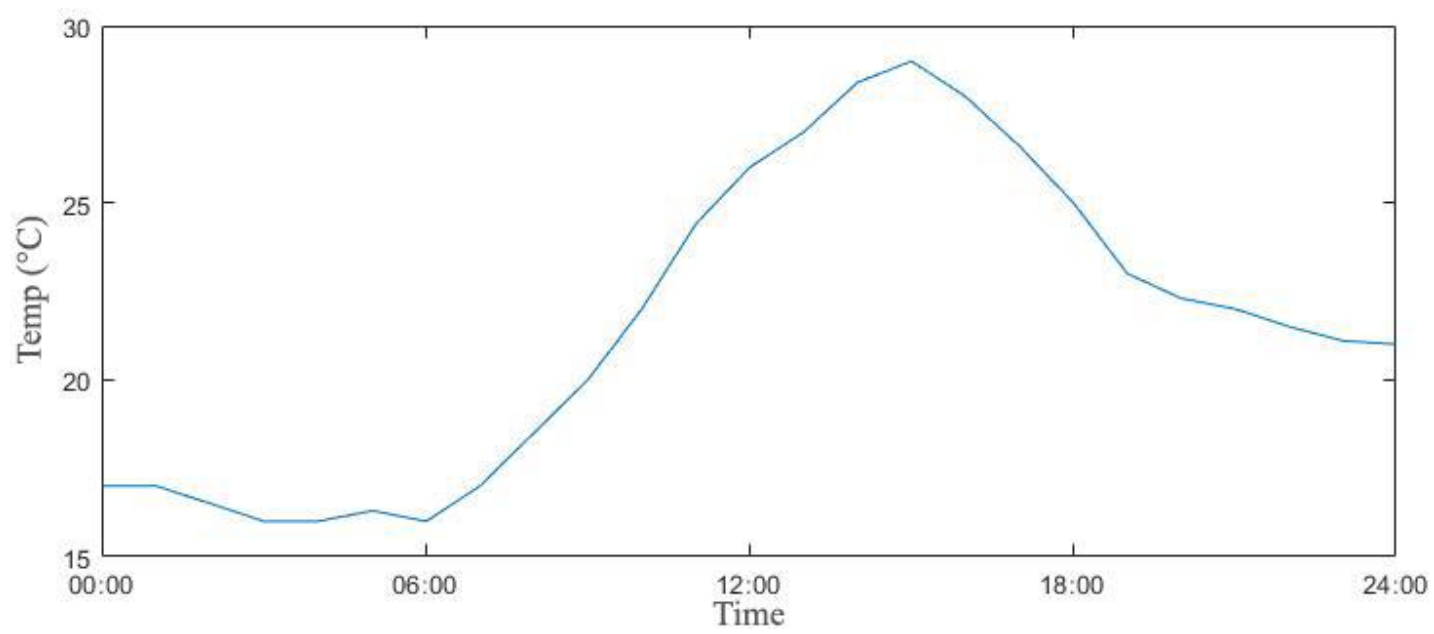

Figure 4. $T_{\text {out }}$ of Shanghai at 28 April.

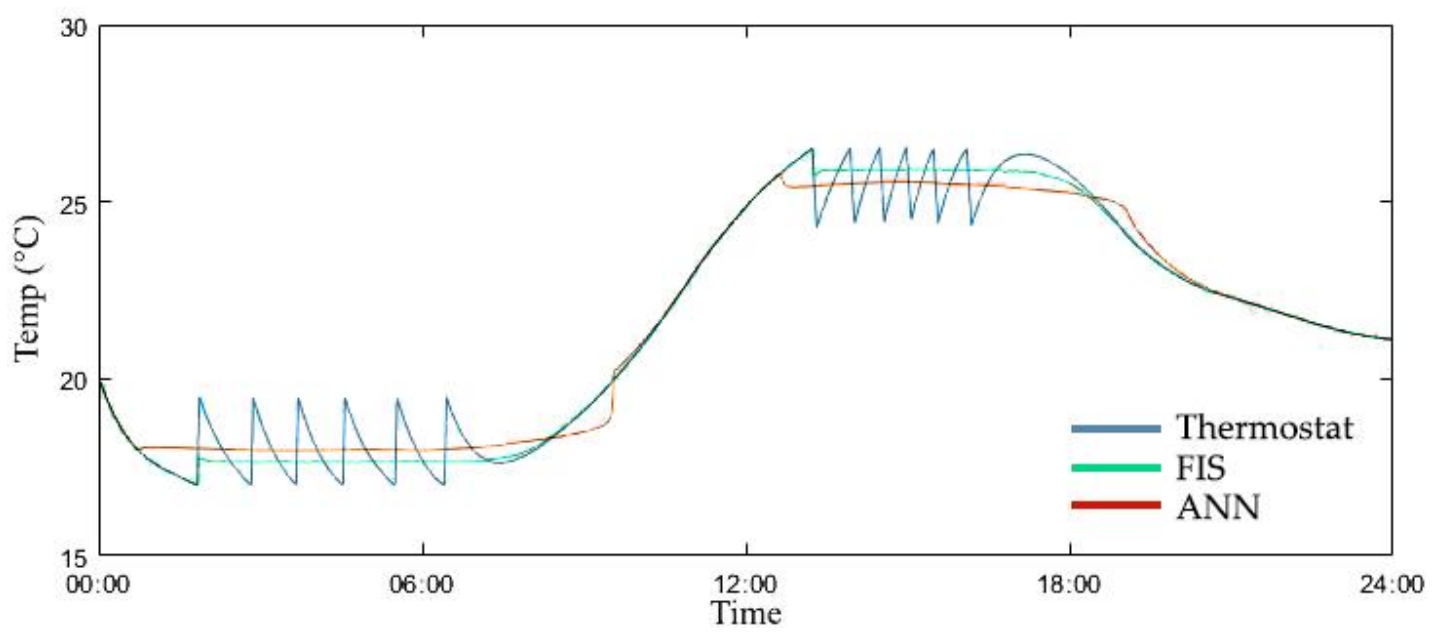

Figure 5. Changes of $T_{r m}$ by each controller.

Figure 5 describes the quite improved control patterns controlled by the FIS control, and it effectively reduces the range of the temperature changing. Except for the position where the thermal control begins to send signals for heating and cooling supply air, most sections of the graph show improved consistent trends compared to the thermostat. It shows the more improved performance of changes in $T_{r m}$ within the $T_{\text {set }}$ by the ANN control. Comparing the suppression of overshoots at the point where control begins and the temperature consistently maintained at even wider time range, it can be seen that this control controls indoor temperatures more effectively than FIS control. That is because data-driven and learned algorithms effectively work to control $T_{r m}$ unless an outlier is entered outside the range of the data from which the regression analysis was made.

\subsection{Energy Transfer}

In Figures 6-8, it can be clearly confirmed that the distinct characteristics of heating and cooling gains changed to maintain $T_{s e t}$ by the three different controllers. In the case of the thermostat, as in $T_{r m}$ graph pattern, there are constant and regular changes of heating gain, from 0 to 12 on the gain axis from 02:00 to 06:30 and 13:00 to 16:00 on the time axis. In the case of the FIS control, it displays a very complex aspect, which in turn is reversed with $T_{r m}$ graph in Figure 5. Although there is a continuous energy supply, the overall low level of heating and cooling energy is identified, and the maximum energy requirements are significantly suppressed in the area where the control of the system begins. 


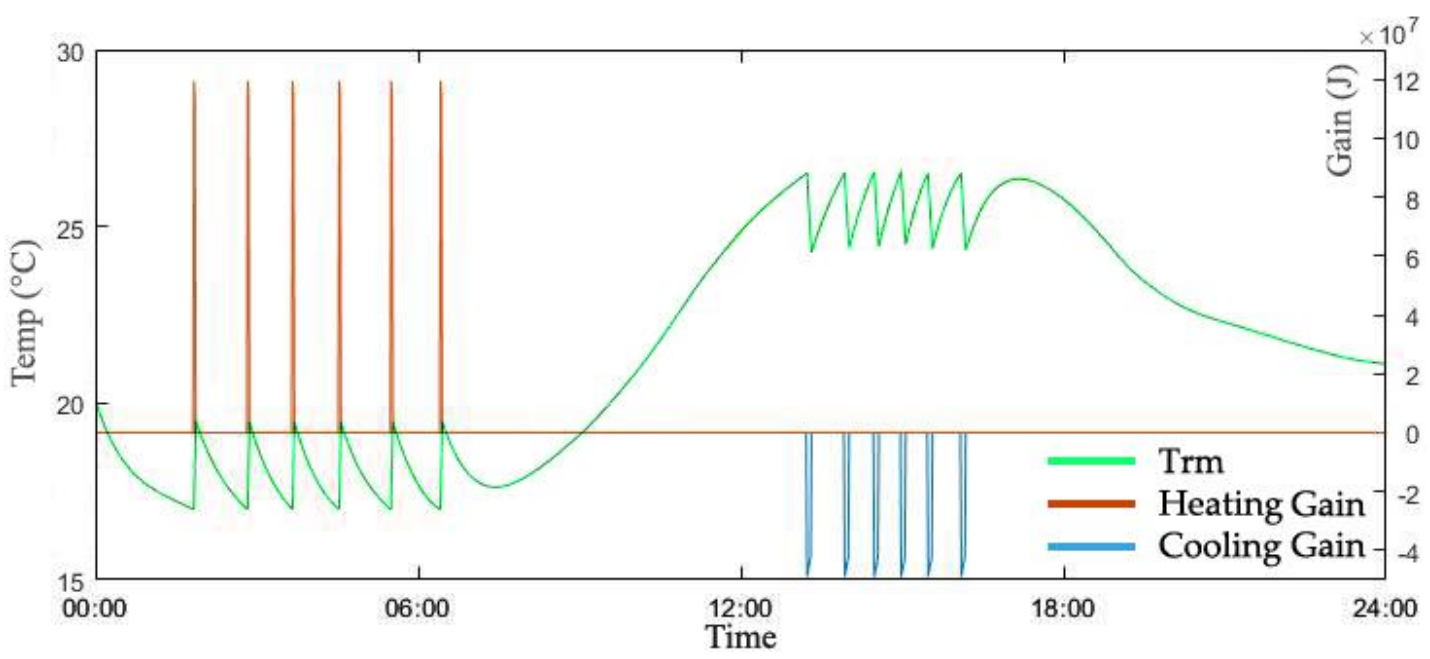

Figure 6. Changes of $T_{r m}$ and energy transfer by the thermostat control.

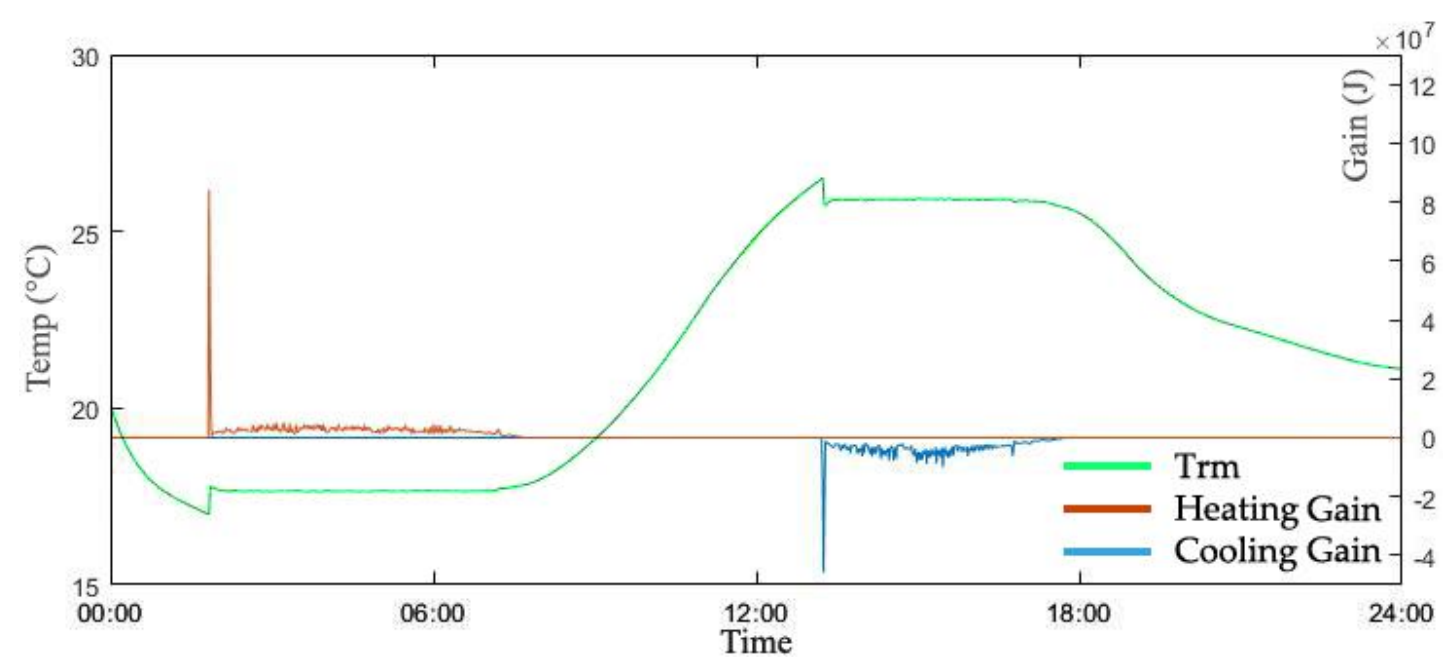

Figure 7. Changes of $T_{r m}$ and energy transfer by the Fuzzy Inference System (FIS) control.

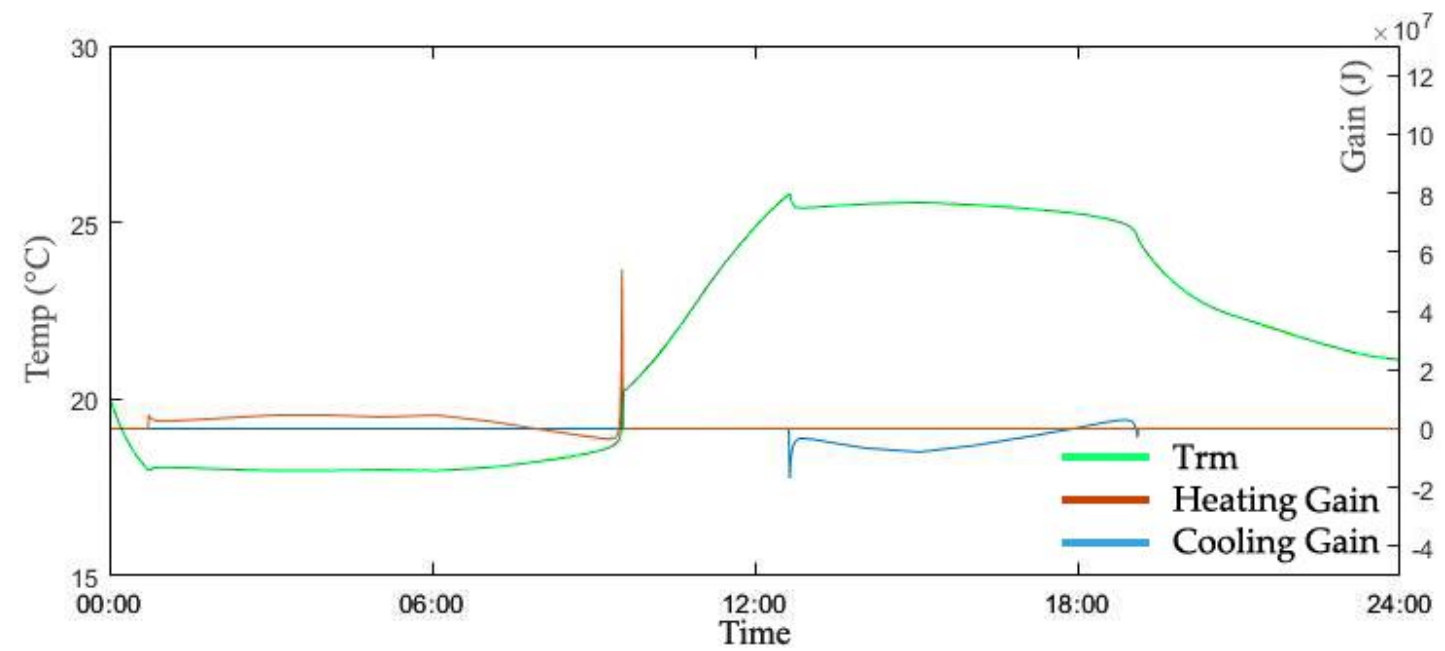

Figure 8. Changes of $T_{r m}$ and energy transfer by the Artificial Neural Network (ANN) control.

As indicated in Figure 8, the advantages of these control effects are more pronounced in the ANN control results. Given the area of the graph, it is confirmed that a bit more energy is required than in the FIS control to maintain a constant indoor comfort level, but the pattern of the change remains 
very smooth, and the overshoots at the point where the beginning of the heating and cooling controls is very effectively inhibited. As previously mentioned, it is confirmed that the major advantages of the network-based learning algorithm are this relatively small change in heating and cooling gain patterns and significant amount of overshoots suppression work from a given range of data.

\section{Discussion}

In Table 2, the performance comparison is described by use of the averages of absolute values of the PMV results from three different controls. The results show somewhat of a deviation from the generally considered thermal comfort level, due to a bit low PMV values derived from low indoor temperatures during the nighttime and due to somewhat high PMV values derived from slightly high setting values of daytime users' metabolic rates and clothing insulation. As indicated, the FIS is $11.34 \%$ less efficient than the thermostat control, but the ANN is $10.69 \%$ more efficient. These results can be potentially related to users' workability in work spaces, but this aspect is not conclusive in this study. The efficiency from the calculation of differences in thermal comfort needs to be addressed at a follow-up research as to how the results of average or standard deviation values is related to any economic or industrial effects in the use of building spaces.

Table 2. Comparison of each thermal comfort.

\begin{tabular}{ccc}
\hline Control & PMV (Avg. of Abs.) & Efficiency (\%) \\
\hline Thermostat & 2.50 & - \\
\hline FIS & 2.78 & $11.34(\downarrow)$ \\
\hline ANN & 2.23 & $10.69(\uparrow)$ \\
\hline
\end{tabular}

In energy use in Table 3, it can be easily confirmed that the FIS control achieves by $2.65 \%$ more efficient than the thermostat control, but the ANN control uses a bit more energy by $5.37 \%$. This comparison is relatively clear because the differences in energy transfer can be directly connected to the cost of energy use. However, for this difference in energy transfer or use, it is not only difficult to interpret exactly what the actual circumstances have caused but also makes it difficult to find improving methods to these results. As indicated in Figures 9-12, the characteristics of two different controls is clearly confirmed. For the FIS, with the exception of sections that go up and down between $0(0 \%)$ and $0.2(20 \%)$ in the opening signal of cooling supply air, the relatively effective control pattern is shown, especially for temperature control, which increases the efficiency of temperature control by limiting the range of changes to within 7 to $8^{\circ} \mathrm{C}$. When manufactured with an actual device, it can help to optimize the capacity of heating coils and the amount of electricity to be used. This aspect is more pronounced in the ANN's graph. For most sections of the damper controls, the opening is maintained at about 0.1 $(10 \%)$ level, and the overshoots from the point of system initialized to about $0.9(90 \%)$ in the FIS is also effectively improved to around $0.5(50 \%)$ by the ANN control. The temperature control is similarly effective compared to the FIS, which has an effective result within a relatively narrow range, except for the overshoots at the system initialization. Not only is it controlled at almost constant temperatures without big changes, but it also almost perfectly suppresses the overshoots at the point of the beginning of system operation.

Table 3. Comparison of each energy transfer.

\begin{tabular}{ccc}
\hline Control & Energy Transfer $\left(\mathbf{k W h} / \mathbf{m}^{2} \cdot\right.$ year) & Efficiency (\%) \\
\hline Thermostat & 1223.87 & - \\
\hline FIS & 1191.40 & $2.65(\uparrow)$ \\
\hline ANN & 1289.62 & $5.37(\downarrow)$ \\
\hline
\end{tabular}




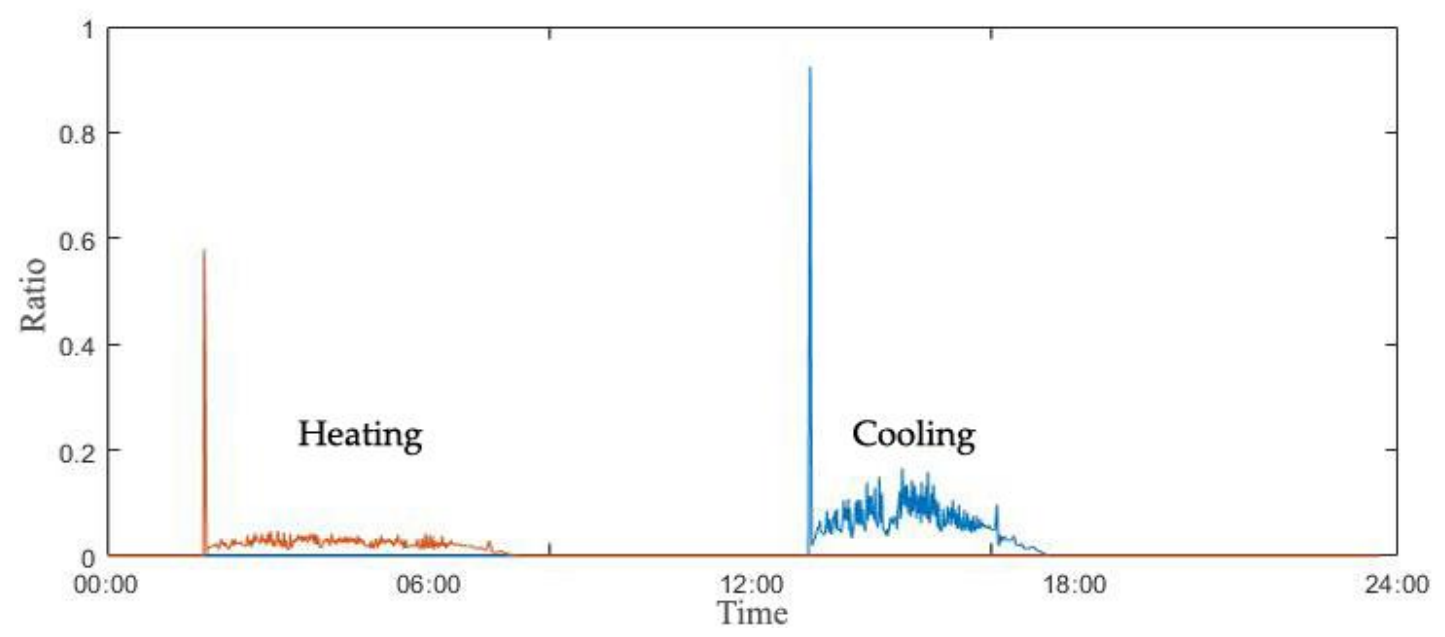

Figure 9. Signals for the amount of supply air by the FIS control.

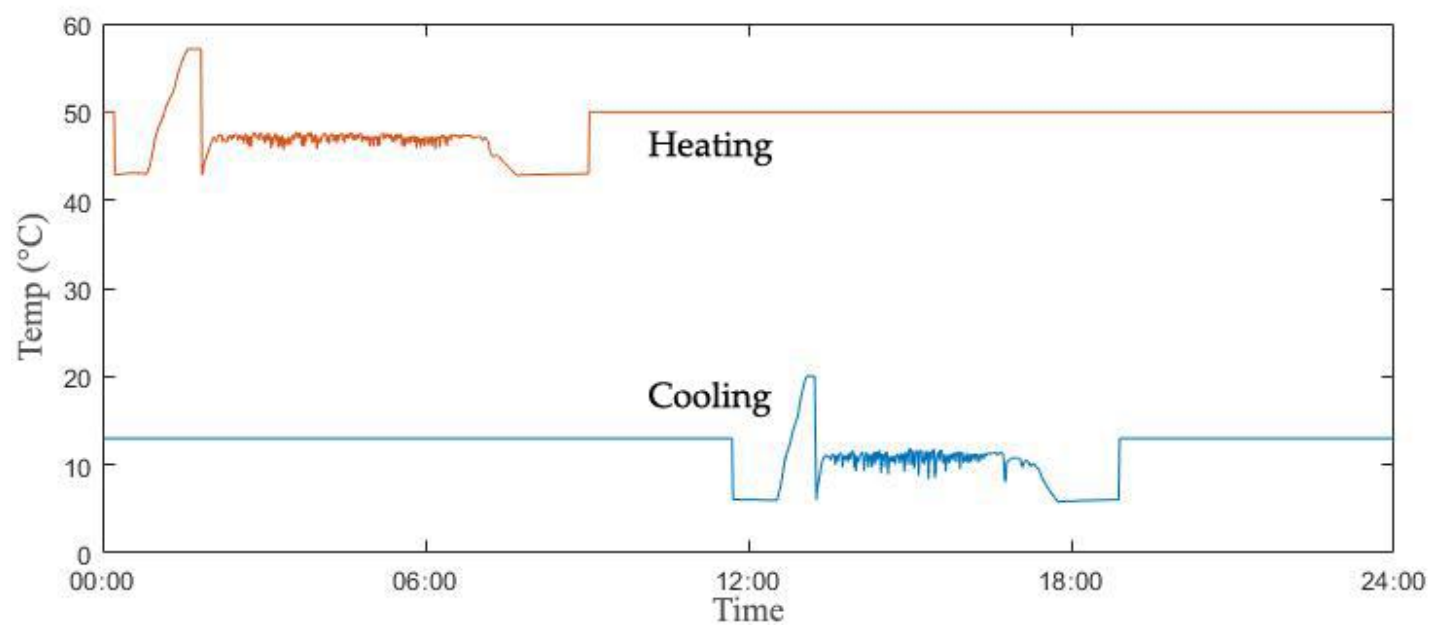

Figure 10. Signals for the temperature of supply air by the FIS control.

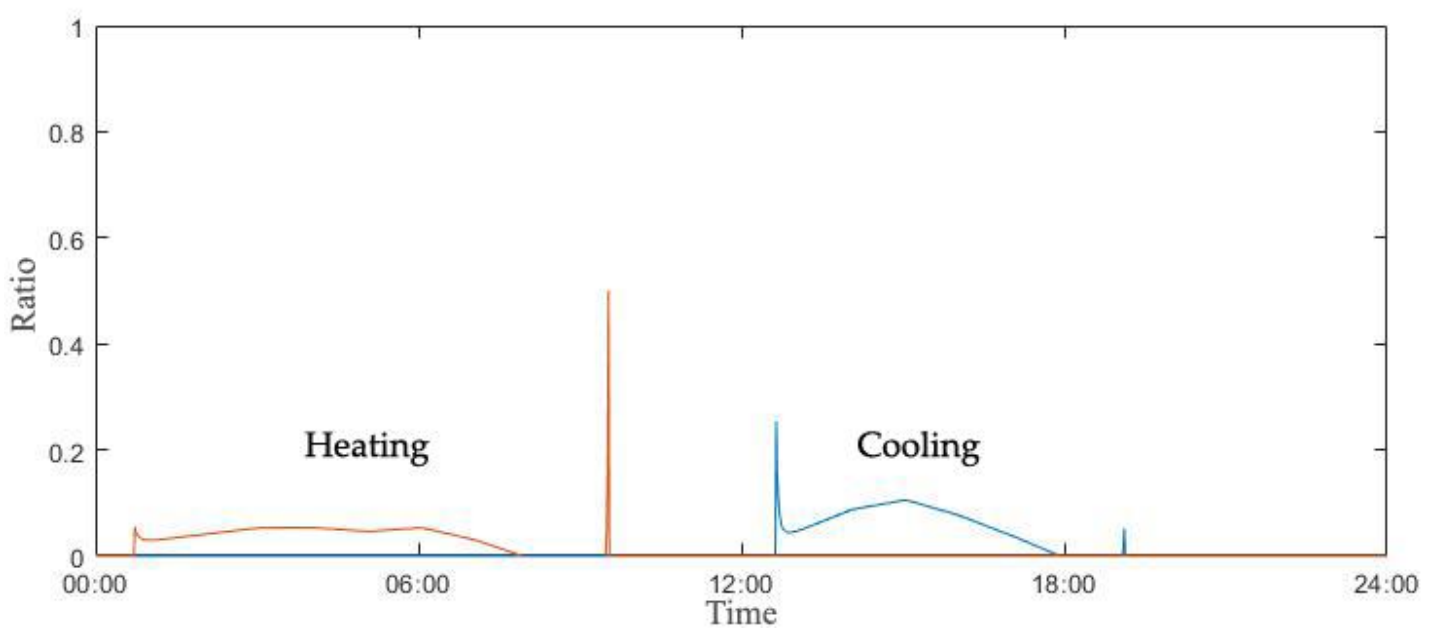

Figure 11. Signals for the amount of supply air by the ANN control. 


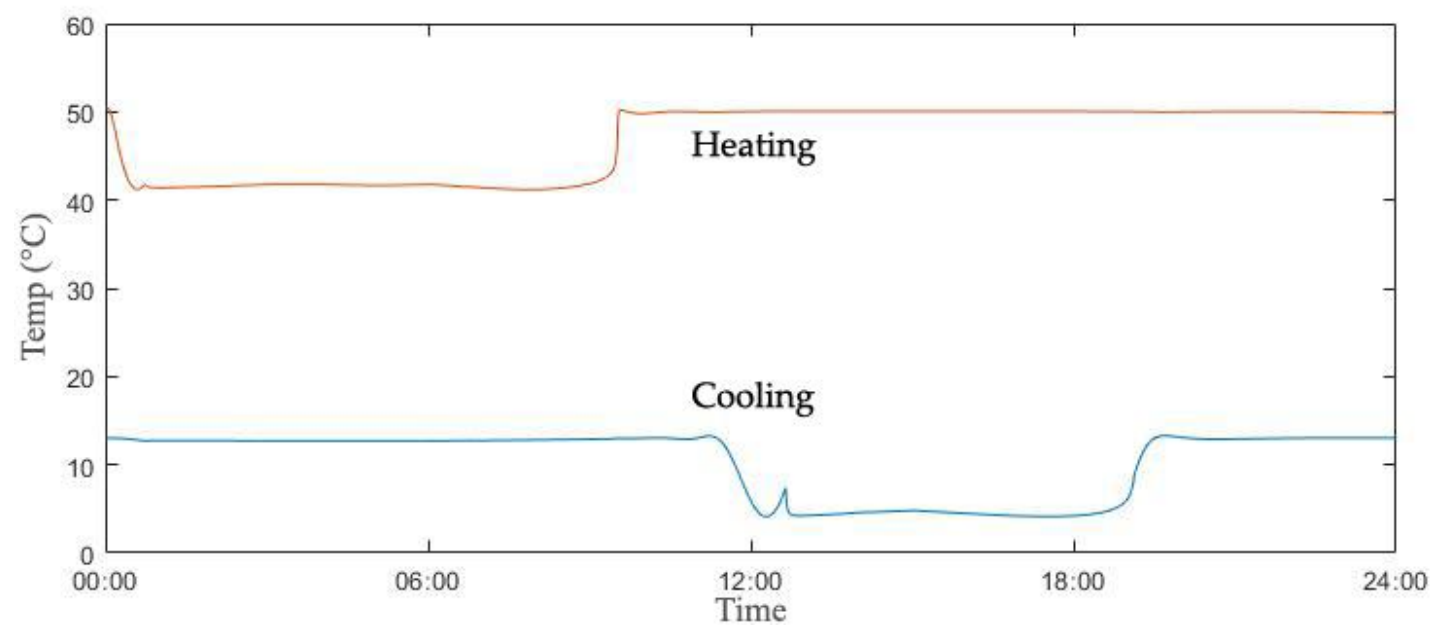

Figure 12. Signals for the temperature of supply air by the ANN control.

As previously mentioned, the ANN model equipped with an adaptive controller inhibited the sudden change of signals in most time ranges where heating and cooling controls were performed, thus implementing a relatively consistent and smooth control pattern. According to some studies about thermal controls, the advantages of the proposed model identified in the results are more pronounced. Although there is a difference between the types of buildings being a warehouse, the neural network model without an adaptive model improved by just $0.7 \%(173.1 \rightarrow 171.9)$ in thermal comfort (the sum of the absolute values of the error to the PMV setting value), and by $1.3 \%\left(115.4 \rightarrow 113.9 \mathrm{kWh} / \mathrm{m}^{2}\right.$.year) in energy consumption. In addition, in the case of a single space in the residential, the neural network model with fuzzy deterministic module improved by $4.2 \%(2.80 \rightarrow 2.68)$ in thermal comfort (the root mean square error for the PMV setting value), but the energy efficiency deteriorated by $1.3 \%$ ( $253.7 \rightarrow$ $291.6 \mathrm{kWh} / \mathrm{m}^{2}$.year). This advantage can also be attributed to the performance to reduce the overshoots in the initial phase through the network-based learning structure not just the performance of mitigating fluctuations of control patterns. The overshoots in areas where air conditioning and heating began were also effectively reduced from about $20 \%$ to $60 \%$. It is assumed that this aspect can contribute to the reduction of actual installation and maintenance costs by reducing the operating time of the dampers to be installed and optimizing the capacity of the resistance coil for heating. Despite possible savings in this aspect of cost, the effect is expected to be greater as the thermal comfort of the actual users is shown to be improved by more than $10 \%$. However, further research on what economic effects this effect of comfort will lead to is imperative, and it could be necessary to analyze whether the reduction in the range of $T_{\text {set }}$ or an adaptive controller will result in lower heating and cooling energy transfer than the thermostat and the FIS controls.

\section{Conclusions}

In this research, it was confirmed that the proposed network-based learning control worked properly to improve thermal comfort levels without any sharp increases of energy consumption. In terms of heating and cooling control signals, it effectively reduced operational overshoots and signal fluctuations, which is directly related to design thermal system's capacity. The artificial neural network algorithm equipped with an adaptive model that adjusts set-point temperature according to the comfort level performed about 10.7\% improvement over the thermostat model and about $19.8 \%$ improvement over the fuzzy-based model, respectively. In the consistency of thermal comfort levels, despite being able to effectively maintain the comfort level high, the energy consumption level was found to be just $5.4 \%$ higher than the thermostat model and $8.2 \%$ higher than the fuzzy-based model.

As a result, the network-based learning control successfully responded to spatial and occupant conditions to improve the thermal comfort levels; however, due to this operational characteristic, the energy consumption was slightly increased. This is an inevitable result of the need for additional energy 
use in the operation of more precise thermal controls in buildings. Thus, a follow-up research will perform to develop a systematic and comprehensive control rule to define how much the precise and sensitive control could increase energy consumption in the operation. This approach will lead to the development of a more comprehensive adaptive model that will be accompanied by an improvement in energy efficiency without hindering the performance for indoor thermal comfort, which will be relearned in the network-based learning control.

Author Contributions: Conceptualization, J.A.; methodology, J.A.; software, J.A.; validation, J.A.; formal analysis, J.A.; investigation, J.A.; resources, J.A..; data curation, J.A.; writing-original draft preparation, S.H.Y. and J.A.; writing-review and editing, S.H.Y. and J.A.; visualization, S.H.Y. and J.A.; supervision, S.H.Y. and J.A. project administration, S.H.Y.; funding acquisition, S.H.Y. All authors have read and agreed to the published version of the manuscript.

Funding: This work was supported by the research grant of Cheongju University (1 March 2019 28 February 2021).

Conflicts of Interest: The authors declare no conflict of interest. The funders had no role in the design of the study; in the collection, analyses, or interpretation of data; in the writing of the manuscript, or in the decision to publish the results.

\section{Nomenclature}

\begin{tabular}{|c|c|c|c|}
\hline$A$ & area of material $(\mathrm{s})\left(\mathrm{m}^{2}\right)$ & $Q_{\text {loss }}$ & $\begin{array}{l}\text { heat loss by convection and } \\
\text { transmission }(\mathrm{J})\end{array}$ \\
\hline $\mathrm{Cv}$ & $\begin{array}{l}\text { specific heat capacity at constant } \\
\text { volume }(\mathrm{J} / \mathrm{kg} \cdot \mathrm{K})\end{array}$ & $Q_{\text {gain }}$ & $\begin{array}{l}\text { heat gain by convection and } \\
\text { transmission }(\mathrm{J})\end{array}$ \\
\hline$C_{p}$ & $\begin{array}{l}\text { specific heat capacity at constant } \\
\text { pressure }(\mathrm{J} / \mathrm{kg} \cdot \mathrm{K})\end{array}$ & $R$ & thermal resistance $(\mathrm{m} \cdot \mathrm{K} / \mathrm{W})$ \\
\hline$D$ & thickness of material(s) (m) & $t$ & time \\
\hline$h_{\text {in }}, h_{\text {out }}$ & $\begin{array}{l}\text { convection heat transfer coefficient } \\
\text { inside, outside }\left(\mathrm{W} / \mathrm{m}^{2} \cdot \mathrm{K}\right)\end{array}$ & $T_{h t}$ & air temperature from heater $\left({ }^{\circ} \mathrm{C}\right)$ \\
\hline$k$ & thermal conductivity $(\mathrm{W} / \mathrm{m} \cdot \mathrm{K})$ & $T_{\text {out }}$ & temperature of outside \\
\hline$\dot{m}_{h t}$ & mass flow-rate from system $(\mathrm{kg} / \mathrm{h})$ & $T_{r m}$ & temperature of room $\left({ }^{\circ} \mathrm{C}\right)$ \\
\hline$\dot{m}_{\text {in }}$ & mass flow-rate inside room $(\mathrm{kg} / \mathrm{h})$ & $T_{\text {set }}$ & temperature of thermostat set-point $\left({ }^{\circ} \mathrm{C}\right)$ \\
\hline$\dot{m}_{\text {out }}$ & mass flow-rate outside room $(\mathrm{kg} / \mathrm{h})$ & $U$ & internal energy $(\mathrm{J})$ \\
\hline$m_{r m \cdot a i r}$ & mass flow-rate in room air $(\mathrm{kg})$ & W & work $(J)$ \\
\hline
\end{tabular}

\section{References}

1. Zhuang, M.; Atherton, D. Automatic tuning of optimum PID controllers. IEE Proc. D Control. Theory Appl. 1993, 140, 216-224. [CrossRef]

2. Tan, W.; Liu, J.; Fang, F.; Chen, Y. Tuning of PID controllers for boiler-turbine units. ISA Trans. 2004, 43, 571-583. [CrossRef]

3. Kull, T.M.; Thalfeldt, M.; Kurnitski, J. PI Parameter Influence on Underfloor Heating Energy Consumption and Setpoint Tracking in nZEBs. Energies 2020, 13, 2068. [CrossRef]

4. Jin, J.; Huang, H.; Sun, J.; Pang, Y. Study on fuzzy self-adaptive PID control system of biomass boiler drum water. J. Sustain. Bioenergy Syst. 2013, 3, 93-98. [CrossRef]

5. Fazzolari, M.; Alcalá, R.; Nojima, Y.; Ishibuchi, H.; Herrera, F. A review of the application of multiobjective evolutionary fuzzy systems: Current status and further directions. IEEE Trans. Fuzzy Syst. 2012, 21, 45-65. [CrossRef]

6. Szoplik, J. Forecasting of natural gas consumption with artificial neural networks. Energy 2015, 85, $208-220$. [CrossRef]

7. Zhang, J.; Ou, J.; Sun, D. Study on fuzzy control for HVAC SYSTEMS. ASHRAE Trans. 2003, $109,27$.

8. Alcalá, R.; Benítez, J.M.; Casillas, J.; Cordón, O.; Pérez, R. Fuzzy control of HVAC systems optimized by genetic algorithms. Appl. Intell. 2003, 18, 155-177. [CrossRef] 
9. Wong, S.; Wan, K.K.; Lam, T.N. Artificial neural networks for energy analysis of office buildings with daylighting. Appl. Energy 2010, 87, 551-557. [CrossRef]

10. Jung, Y.-H. Analysis of air flow distribution according to the positions of computer room air conditioning and perforated plate in a server room of data center. KIEAE J. 2019, 19, 83-88. [CrossRef]

11. Bakhtiari, H.; Akander, J.; Cehlin, M.; Hayati, A. On the performance of night ventilation in a historic office building in Nordic climate. Energies 2020, 13, 4159. [CrossRef]

12. Soyguder, S.; Alli, H. Predicting of fan speed for energy saving in HVAC system based on adaptive network based fuzzy inference system. Expert Syst. Appl. 2009, 36, 8631-8638. [CrossRef]

13. Ahn, J.; Cho, S.; Chung, D.H. Analysis of energy and control efficiencies of fuzzy logic and artificial neural network technologies in the heating energy supply system responding to the changes of user demands. Appl. Energy 2017, 190. [CrossRef]

14. Moon, J.W.; Ahn, J. Improving sustainability of ever-changing building spaces affected by users' fickle taste: A focus on human comfort and energy use. Energy Build. 2020, 208. [CrossRef]

15. Singh, M.; Attia, S.; Mahapatra, S.; Teller, J. Assessment of thermal comfort in existing pre-1945 residential building stock. Energy 2016, 98, 122-134. [CrossRef]

16. Ahn, J.; Chung, D.H.; Cho, S. Performance analysis of space heating smart control models for energy and control effectiveness in five different climate zones. Build. Environ. 2017, 115. [CrossRef]

17. Zhong, L.; Yuan, J.; Fleck, B. Indoor environmental quality evaluation of lecture classrooms in an institutional building in a cold climate. Sustainability 2019, 11, 6591. [CrossRef]

18. Ahn, J. Performance analyses of temperature controls by a network-based learning controller for an indoor space in a cold area. Sustainability 2020, 12. [CrossRef]

19. Simanic, B.; Nordquist, B.; Bagge, H.; Johansson, D. Influence of user-related parameters on calculated energy use in low-energy school buildings. Energies 2020, 13, 2985. [CrossRef]

20. Ren, Z.; Chen, D. Modelling study of the impact of thermal comfort criteria on housing energy use in Australia. Appl. Energy 2018, 210, 152-166. [CrossRef]

21. Park, S.; Cho, S.; Ahn, J. Improving the quality of building spaces that are planned mainly on loads rather than residents: Human comfort and energy savings for warehouses. Energy Build. 2018, 178. [CrossRef]

22. Sung, L.Y.; Ahn, J. Comparative analyses of energy efficiency between on-demand and predictive controls for buildings' indoor thermal environment. Energies 2020, 13, 1089. [CrossRef]

23. Ahn, J.; Chung, D.H.; Cho, S. Network-based energy supply optimal system in the condition where both heating and cooling are required simultaneously in a swing season. Intell. Build. Int. 2017, 10. [CrossRef]

24. Yang, S.; Wan, M.P.; Ng, B.F.; Zhang, T.; Babu, S.; Zhang, Z.; Chen, W.; Dubey, S. A state-space thermal model incorporating humidity and thermal comfort for model predictive control in buildings. Energy Build. 2018, 170, 25-39. [CrossRef]

25. Ahn, J.; Cho, S. Anti-logic or common sense that can hinder machine's energy performance: Energy and comfort control models based on artificial intelligence responding to abnormal indoor environments. Appl. Energy 2017, 204. [CrossRef]

26. Lee, S.; Joe, J.; Karava, P.; Bilionis, I.; Tzempelikos, A. Implementation of a self-tuned HVAC controller to satisfy occupant thermal preferences and optimize energy use. Energy Build. 2019, 194, 301-316. [CrossRef]

27. Millers, R.; Pelite, U. Survey of control characteristics of circular air dampers in variable air volume ventilation systems. Energy Procedia 2016, 96. [CrossRef]

28. Bergman, T.L.; Incropera, F.P.; DeWitt, D.P.; Lavine, A.S. Fundamentals of Heat and Mass Transfer; John Wiley \& Sons: New York, NY, USA, 2018.

29. Parson, K. Thermal Comfort; Informa UK Limited: Colchester, UK, 2002.

30. Engineering Toolbox. Recommended Indoor Temperatures Summer and Winter. Available online: http: //www.engineeringtoolbox.com (accessed on 11 November 2016).

31. Petković, D.; Protić, M.; Shamshirband, S.; Akib, S.; Raos, M.; Marković, D. Evaluation of the most influential parameters of heat load in district heating systems. Energy Build. 2015, 104, 264-274. [CrossRef] 
32. Braspenning, P.; Thuijsman, F.; Weijters, A. Artificial Neural Networks; Springer: Berlin/Heidelberg, Germany, 1995.

33. Vamsi, R. What's a Neural Network? Available online: https://medium.com (accessed on 11 November 2020).

Publisher's Note: MDPI stays neutral with regard to jurisdictional claims in published maps and institutional affiliations.

(C) 2020 by the authors. Licensee MDPI, Basel, Switzerland. This article is an open access article distributed under the terms and conditions of the Creative Commons Attribution (CC BY) license (http://creativecommons.org/licenses/by/4.0/). 